\title{
A PERCEPÇÃO DE DISCENTES SOBRE A FORMAÇÃO DE PROFESSORES NO CONTEXTO DA POLÍTICA DE EXPANSÃO DO ENSINO SUPERIOR
}

\author{
Renan Arjona Souza ${ }^{\mathrm{i}}$ \\ Nádia Maria Pereira Souza ${ }^{\text {ii }}$
}

\begin{abstract}
Resumo: Este artigo analisa o significado social da formação de professores a partir da política de expansão e interiorização do ensino superior implementada à partir do ano de 2003 no Brasil. Para tal, além do levantamento de dados em documentos oficiais federais e institucionais, realizou-se uma pesquisa qualitativa com 39 discentes ingressantes dos primeiros cursos de licenciatura de um Campus Universitário Federal na Baixada Fluminense, região metropolitana do Rio de Janeiro (BR). Para a coleta de dados foi aplicado um questionário semiestruturado o qual foi explorado com base na análise de conteúdo de Bardin (1979). Os resultados da investigação, entre outros aspectos, evidenciava que a implementação do Campus da Universidade na Baixada Fluminense parece estar contribuindo com a mobilidade social e a redução das desigualdades sociais na região, ainda que de forma lenta.
\end{abstract}

Palavras-chave: Ensino superior. Formação de Professores. Baixada Fluminense.

\begin{abstract}
This article analyzes the social meaning of teacher education based on the policy of expansion and internalization of higher education implemented since 2003 in Brazil. To do this, in addition to data collection in official federal and institutional documents, a qualitative research was carried out with 39 students from the first undergraduate courses of a Federal University Campus in Baixada Fluminense, metropolitan region of Rio de Janeiro (BR). For the data collection, a semi-structured questionnaire was applied which was explored based on the content analysis of Bardin (1979). The results of the research, among other aspects, showed that the implementation of the University Campus in the Baixada Fluminense seems to be contributing to social mobility and the reduction of social inequalities in the region, albeit slowly.
\end{abstract}

Keywords: Higher education; Teacher training; Baixada Fluminense.

Resumen: Este artículo analiza el significado social de la formación de profesores a partir de la política de expansión e interiorización de la enseñanza superior implementada a partir del año 2003 en Brasil. Para ello, además del levantamiento de datos en documentos oficiales federales e institucionales, se realizó una investigación cualitativa con 39 discentes ingresantes de los primeros cursos de licenciatura de un Campus Universitario Federal en la Baixada Fluminense, región metropolitana de Río de Janeiro (BR). Para la recolección de datos se aplicó un cuestionario semiestructurado que se exploró sobre la base del análisis de contenido de Bardin (1979). Los resultados de la investigación, entre otros aspectos, evidenciaban que la implementación del Campus de la Universidad en la Baixada Fluminense parece estar contribuyendo con la movilidad social y la reducción de las desigualdades sociales en la región, aunque de forma lenta.

Palabras clave: Enseñanza superior; Formación de profesores; Bajada Fluminense. 


\section{Introdução}

Existe uma demanda crescente de estudos sobre a expansão e interiorização do ensino superior e seus impactos na sociedade brasileira. Pesquisas nesta área têm ganhado destaque por produzirem informações necessárias ao poder público, que tem priorizado estas formações nos últimos Planos Nacionais de Educação como meio possível de promoção de transformação social.

Cabe destacar que o termo "transformação social" tem concepções distintas em diferentes áreas do conhecimento. Na perspectiva das ciências sociais, por exemplo, é definida por Castles (2002) como um campo de investigação que poderá e deverá levar à formulação de "receitas" positivas para a ação social e política, de modo a auxiliar as comunidades a melhorar os seus meios de subsistência e a lidar com as consequências das transformações globais.

Neste contexto, este artigo apresenta os resultados de um estudo sobre o significado social de uma política pública nacional de expansão e interiorização do ensino superior com reflexos na Baixada Fluminense, Estado do Rio de Janeiro - Brasil, a partir do ano de 2003, nos mandatos do presidente Luis Inácio Lula da Silva.

A Baixada Fluminense conta com cerca de 3.200.000 habitantes, segundo os dados do Censo do IBGE de 2010, e compõe com a capital fluminense uma área metropolitana de alta densidade demográfica. Esta região possui um dos maiores centros comerciais do Estado e concentração de algumas indústrias, como a de cosméticos, por exemplo.

Uma característica da Baixada Fluminense está na grande concentração de jovens. Como exemplo, no Censo 2010 do IBGE, em apenas 3 das 21 faixas etárias, que compreendem as idades entre 10 e 24 anos, encontram-se 26,5\% da população residente. Esta população jovem reflete o quantitativo de 123.531 estudantes matriculados em escolas de ensino médio regular e normal/magistério, conforme o Educacenso do ano de 2015.

Entretanto, mesmo apresentando desempenho econômico maior que outras regiões do Estado do Rio de Janeiro, um grande percentual da população ainda ocupa postos de trabalho na capital fluminense. A Baixada Fluminense apresenta baixos índices sociais e educacionais e são poucas as opções de instituições de ensino superior públicas na região.

Realidades semelhantes podem ser percebidas em várias regiões do Brasil, com localidades marcadas por alta demanda de formação e profundas desigualdades sociopolíticoculturais e econômicas.

Nesta perspectiva, de forma geral a referência deste estudo abordou aspectos da formação acadêmica em consonância com uma política pública, que pode potencializar (ou não) a função e 
o engajamento das Universidades Federais como expressão das políticas do governo no auxílio da superação da miséria e na redução das desigualdades sociais.

Para este artigo, entretanto, relacionamos os resultados que se referem à percepção dos discentes sobre o impacto do processo de formação de professores a partir da oferta de três cursos de licenciatura no Campus Nova Iguaçu ${ }^{1}$ da Universidade Federal Rural do Rio de Janeiro (UFRRJ), lócus deste estudo, inaugurado no ano de 2006, fruto do projeto de expansão anteriormente descrito.

Na metodologia, apresenta-se a pesquisa de campo realizada no estudo, a forma como foi organizada e a sua fundamentação teórica. Nos resultados, apresentam-se os dados obtidos relacionados a algumas concepções teóricas, pautados por duas categorias descritas na pesquisa.

O estudo de campo de natureza qualitativa teve por objetivo geral Analisar o significado social da expansão do ensino superior para a Baixada Fluminense, a partir da implementação dos cursos de Licenciatura no Campus Nova Iguaçu da Universidade Federal Rural do Rio de Janeiro. Os resultados obtidos apontam indicadores de promoção de oportunidade de ascensão social através da ampliação da oferta de vagas e mais condições para a permanência na Universidade. Estes resultados, portanto, podem contribuir para a defesa das Instituições Federais de Ensino Superior (IFES), tendo em vista que a redução de investimentos públicos na expansão e manutenção destas instituições pode acentuar o contexto de desigualdade social no Brasil.

\section{Metodologia}

A pesquisa foi realizada no Campus Nova Iguaçu da Universidade Federal Rural do Rio de Janeiro (UFRRJ). Os sujeitos foram os discentes ingressantes dos três primeiros cursos de licenciatura deste campus no período de 2006 a 2009 e que ainda estavam com matrícula ativa no semestre letivo 2015/2.

Como critério, estes discentes foram escolhidos por não concluírem a graduação nos tempos mínimos estabelecidos nos Programas Pedagógicos dos Cursos e, desta forma, contribuíram com suas histórias para com a pesquisa em função da maior probabilidade de terem enfrentado problemas durante o curso da graduação. Ou seja, se tornou enriquecedor para a pesquisa ouvir destes discentes quais são os desafios para ingresso e permanência na Universidade.

\footnotetext{
${ }^{1}$ O Campus Nova Iguaçu da UFRRJ surgiu como o décimo Instituto desta Universidade, chamado Instituto Multidisciplinar (IM).

Revista Interinstitucional Artes de Educar. Rio de Janeiro, V. 4, N.1- pág. 186 - 203 - (jan. - abr. de 2018): "Questões contemporâneas sobre a Educação Especial na Perspectiva da Educação Inclusiva" 
Como procedimento de coleta de dados foi aplicado um questionário, com o qual foram obtidos 39 respondentes $(48,75 \%)$ das 80 pessoas da população pesquisada: 15 respondentes do curso de História, 15 respondentes do curso de Matemática e 9 respondentes do curso de Pedagogia. O tipo de amostragem por acessibilidade ou conveniência demonstrou-se o mais indicado, apesar de ser não probabilística.

A utilização de uma amostragem não probabilística neste levantamento de campo se justifica por este apresentar características que dispensam a utilização de amostragem probabilística, dentre as indicadas por Mattar (1996, p. 157), como: a obtenção de uma amostra de dados que reflitam precisamente a população não é o propósito principal da pesquisa; se não há intenção de generalizar os dados obtidos na amostra, então não haverá preocupações quanto à amostra ser mais ou menos representativa da população; e às limitações de tempo, recursos financeiros, materiais e pessoas, necessários para a realização de uma pesquisa com amostragem probabilística.

Como estratégias de tratamento dos dados variam em função do plano de pesquisa, Gomes (2009) destaca que, em pesquisas qualitativas, a análise e interpretação não têm por finalidade contar opiniões ou pessoas, porque,

Seu foco é, principalmente, a exploração do conjunto de opiniões e representações sociais sobre o tema que pretende investigar. Este estudo do material não precisa abranger a totalidade das falas e expressões dos interlocutores porque, em geral, a dimensão sociocultural das opiniões e representações de um grupo que tem as mesmas características, costumam ter muitos pontos em comum ao mesmo tempo que apresentam singularidades próprias da biografia de cada interlocutor (GOMES, 2009, p. 79).

Ainda segundo este autor, também é preciso considerar a diversidade de opiniões e crenças que ocorrem dentro de um mesmo segmento social, caminhando em direção tanto ao que é homogêneo quanto no que se diferencia no mesmo grupo.

A partir deste entendimento, para análise e interpretação dos dados optamos pela análise de conteúdo de Bardin (1979), que permite depurar as informações organizando-as em categorias. A análise de conteúdo foi muito bem sistematizada por Bardin, que a definiu como um

conjunto de técnicas de análise das comunicações visando obter, por procedimentos sistemáticos e objetivos de descrição do conteúdo das mensagens, indicadores (quantitativos ou não) que permitem a inferência de conhecimentos relativos às condições de produção/recepção (variáveis inferidas) destas mensagens (BARDIN, 1979, p.42). 
Dentre as diferentes técnicas que compõem a análise de conteúdo, a análise temática se mostrou mais adequada para tratamento dos dados. Nesta técnica, o conceito central é o tema, que pode ser apresentado através de uma palavra, frase ou um resumo, sempre de acordo com a finalidade do estudo.

A partir da análise de conteúdo, o agrupamento das perguntas permitiu a elaboração de algumas categorias temáticas, detalhadas em duas categorias: a escolha do curso de graduação e a percepção sobre a formação recebida e sua relação com a resolução das desigualdades. Estas categorias trouxeram algumas impressões, situações e consequências, fruto da vivência dos discentes em um campus universitário recém-inaugurado que ainda se consolidava.

\section{Resultados}

$\mathrm{Na}$ análise das duas categorias a seguir, as respostas foram numeradas aleatoriamente de 1 a 39 em cada questão, a fim de assegurar o anonimato dos informantes do questionário.

\section{A "escolha do curso de graduação"}

Uma das perguntas feitas no questionário foi: Por que escolheu este curso de graduação para estudar? Dos informantes do levantamento de campo, 36 (trinta e seis) pessoas responderam esta questão. Destes, 27 (75\%) ressaltaram a “identificação com a disciplina/docência" como motivo da sua escolha, 4 respondentes (11\%) ressaltaram o emprego. Estas foram as principais respostas, também havendo menção a "curso menos concorrido" $(5,5 \%)$, indicação $(3 \%)$ e outros $(5,5 \%)$.

Nesta questão, destaca-se a maioria dos(as) informantes que revelaram como motivo para a escolha do curso a identificação com a docência ou a disciplina à qual lecionará como professor(a). Dois informantes ilustram este argumento: "Pelo desejo de tornar-me professor" (R34) e "Meu objetivo principal é ser professora e História é a disciplina que quero lecionar" (R2).

Ser professor no Brasil, salvo às exceções, parece ser sinônimo de enfrentamento de diversas dificuldades, como baixos salários, desvalorização da carreira, violência nas escolas e precariedade na infraestrutura. Infelizmente é comum ouvir este tipo de discurso, pois estes problemas são propagados pela mídia e permeiam as mentes dos estudantes antes de ingressar na Universidade. A resposta do informante a seguir constitui uma justificativa diferenciada para a escolha da profissão: "Porque sempre convivi com professores e sempre gostei da profissão apesar das dificuldades" (R5). 
Ao discorrer sobre a atual situação da formação de professores no Brasil, Saviani (2011) afirma que:

Ao fim e ao cabo, o que se revela permanente é a precariedade das políticas formativas, cujas sucessivas mudanças não lograram estabelecer um padrão minimamente consistente de preparação docente para fazer face aos problemas enfrentados pela educação escolar em nosso país (SAVIANI, 2011, p. 10).

Diversos autores retratam as reformas educacionais ao longo dos anos como políticas realizadas de acordo com interesses de organismos internacionais, a serviço de uma ideologia neoliberal, que gerou no modelo de expansão da educação superior no Brasil, como considera Sguissardi (2008, p. 1000), ao se referir ao termo "uma acelerada mercadorização".

Como consequência, estes fatores podem se constituir em um dos motivos que explicam à crescente precarização da profissão docente, tornando os cursos de licenciatura pouco atraentes aos jovens que pensam em ingressar na Universidade.

Gatti e Barreto (2009) mostraram num estudo que 65,1\% dos alunos de Pedagogia atribuem o fato de querer ser professor como principal razão da escolha pela licenciatura, ao passo que esse percentual cai para aproximadamente a metade entre os demais licenciandos $(48,6 \%)$.

Desta forma, dada a correlação entre a pesquisa de Gatti e Barreto (2009) e o levantamento de campo desta pesquisa, a escolha do curso de licenciatura abre espaço para outros fatores que interferem na decisão do candidato que decide ingressar no ensino superior, como a opção da docência como uma espécie de "seguro desemprego" ou melhoria das condições de trabalho exercido sem a formação acadêmica adequada, conforme afirmam dois respondentes a seguir: "Devido ao meu trabalho" (R28) e "Porque atualmente trabalho com Educação Infantil” (R16).

Em relação à pesquisa realizada é possível detectar que muitos informantes são trabalhadores que estudam; uma reconhecida característica da maior parte dos discentes de graduação do Campus Nova Iguaçu da UFRRJ. Dos 39 respondentes, 66,7\% estão trabalhando; sem contar os que desejam trabalhar (18\%) e a opção "outro" $(7,7 \%)$, mencionado por eles como a realização de estágios, por exemplo. Isso mostra a necessidade de obtenção de renda independente da conexão ao curso, fato este diretamente relacionado à condição socioeconômica familiar.

Portanto, chama a atenção quando se entende através da leitura destes dados que a procura por um curso de graduação em licenciatura fica relacionada à experiência do ensino superior como um meio necessário para conseguirem um bom emprego e, por consequência, um 
bom salário. As respostas a seguir ilustram este fato: "Por causa das oportunidades de emprego, faltam muitos professores nessa área" (R32) e "Para ter melhores condições de trabalho" (R29).

Os cursos de licenciatura, desta forma, para estes respondentes, garantem a possibilidade de garantia ou melhoria das condições do seu emprego, e se constituem também como um meio de ascensão social, apesar da precariedade imposta pela escassez de investimentos públicos em formação de professores nas instituições públicas. Pois, "a formação para a docência agrega, e em particular no caso brasileiro, um capital cultural aos estudantes que, ainda mais do que a renda, parece constituir um importante distintivo social”. (GATTI; BARRETO, 2009, p. 167)

Também está relacionada a escolha do curso de graduação a localização do Campus Universitário em questão, como ficou evidente através das respostas à pergunta: Por que escolheu a UFRRJ/Campus Nova Iguaçu?

Dos 39 sujeitos da pesquisa de campo, 37 (trinta e sete) pessoas responderam esta questão. E considerando as unidades de registro e unidades de contexto foi possível identificar duas situações influenciadoras na escolha do Campus Nova Iguaçu da UFRRJ para cursar a graduação: proximidade da residência (31 respondentes) e qualidade do ensino por ser uma IFES (10 respondentes); dentre outros (4 respondentes).

Nesta questão, em virtude da mesma ser aberta, vários respondentes foram enfáticos ao colocar situações variadas como os principais critérios utilizados para a escolha do Campus Nova Iguaçu da UFRRJ. Por este motivo a soma dos critérios ultrapassa 37. Destaco as seguintes respostas:

\author{
Boa universidade e proximidade. (R1) \\ Qualidade e proximidade. (R32) \\ Pela qualidade e proximidade. (R35) \\ Devido à proximidade de casa e ser uma ótima universidade. (R19)
}

Desta forma, pode-se inferir que as falas destes discentes se aproximam da realidade estatística, pois de acordo com Souza (2016), 65,4\% dos 914 ingressantes dos cursos de licenciatura do Campus Nova Iguaçu da UFRRJ (2006-2009) são moradores da Baixada Fluminense, e assim confirmaram que o principal motivo da escolha desta Universidade foi pelo fato da mesma estar localizada próxima da sua residência.

Ao mencionarem a qualidade do ensino, parte destes discentes ilustra um processo histórico no Brasil em que as universidades públicas em geral são referenciais de qualidade em ensino, pesquisa e extensão.

Sguissardi (2008) ao questionar o processo de expansão da educação superior no Brasil sob os interesses do mercado produtivo relembra Anísio Teixeira e o seu entendimento de 
Universidade, quando cita as quatro funções fundamentais desta instituição milenar: a da formação profissional, ao preparar profissionais para as carreiras de base intelectual, científica e técnica; a mais apaixonante atividade humana, a busca do saber; o desenvolvimento do saber humano em todas as suas dimensões; e a transmissão de uma cultura comum nacional. Portanto, as instituições públicas, apesar das dificuldades, podem se constituir em garantias da preservação dos ideais de um sistema de educação superior como direito e bem público, para a formação de profissionais/cidadãos de uma sociedade com o máximo de justiça e igualdade social.

Outra pergunta realizada foi: "Seus pais apoiaram a escolha deste curso? Por quê?" Observou-se também nas respostas a esta pergunta, relação direta com a escolha do curso. Dos 39 (trinta e nove) respondentes do questionário, 36 (trinta e seis) responderam esta questão. Na abordagem dos dados referentes a esta questão, 23 respondentes afirmaram ter apoio dos pais na escolha do curso. Os motivos apontados foram variados, mas podem-se identificar duas tendências de posicionamento: os pais que respeitam as suas escolhas e os pais que incentivam a opção pelo curso de formação de professores.

Em relação a este aspecto, percebe-se que os pais, em geral, respeitaram as escolhas dos filhos, não interferindo na opção do curso. As respostas a seguir exemplificam este aspecto:

Sim. Porque eles nunca se importaram em vigiar as minhas escolhas. Sempre me deixaram bem livre para decidir sobre meu futuro (R4).

Sim. Me apoiariam em qualquer escolha (R12).

Sim, eles nunca se envolveram contra ou a favor da minha escolha acadêmica (R14).

Mesmo sem entender muito eles me apoiaram por ter sido uma decisão minha (R16).

E também se destacam os relatos em referência aos pais que incentivaram a escolha de um curso de formação de professores:

Sim. Meus pais acreditam que qualquer profissão direcionada a educação é respeitada e pode fazer a diferença na vida de uma pessoa (R11).

Sim. Por acharem que professor "nunca fica desempregado" (Que ilusão!) (R10).

Sim. Acreditam que a docência é uma carreira virtuosa (R34).

A profissão docente é uma das mais importantes nas economias modernas, e pode ter se constituído como peça chave nas transformações ocorridas em países com avanços educacionais e tecnológicos.

Além da importância econômica, o trabalho dos professores também tem papel central do ponto de vista político e cultural. O ensino escolar há mais de dois séculos constitui a forma dominante de socialização e de formação nas sociedades modernas e continua se expandindo (GATTI; BARRETO, 2009, p. 15). 
Diante disso, a carreira docente ainda possui atratividade pelas virtudes e importância social que detêm. Ela pode ser vista como um mecanismo de ascensão social em um país com poucas oportunidades para a população com menor renda e escolaridade. Como mostra outra resposta: "Sim, apoiaram porque viram potencial na minha graduação" (R32).

Em relação à origem familiar dos estudantes, o estudo de Gatti; Barreto (2009) mostra que em um país de escolarização tardia como o Brasil, em torno de $10 \%$ deles são oriundos de lares de pais analfabetos e, se somados esses aos que têm pais que frequentaram apenas até a $4^{\mathrm{a}}$ série do ensino fundamental, chega-se aproximadamente à metade dos alunos [de licenciatura], o que denota um claro processo de ascensão desse grupo geracional aos mais altos níveis de formação.

Neste estudo, em relação aos relatos que revelam a falta de apoio dos pais, pode-se inferir que, de forma geral, existe consciência da precarização da profissão e desvalorização salarial no Brasil, como pode ser observado através das falas de 6 respondentes que afirmaram não terem o apoio dos pais na escolha do seu curso.

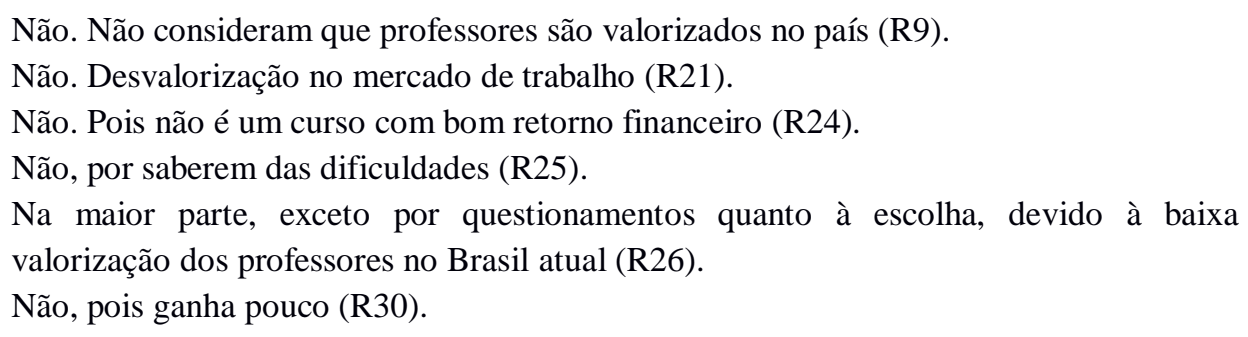

Convém destacar que existem muitos aspectos dos problemas da profissão docente e das políticas de formação de professores no Brasil. Mas é evidente que as condições do exercício do magistério reciprocamente determinam a qualidade da formação docente.

\footnotetext{
Assim sendo, se as condições de trabalho são precárias, isto é, se o ensino se realiza em situação difícil e com remuneração pouco compensadora, os jovens não terão estímulo para investir tempo e recursos numa formação mais exigente e de longa duração. Em consequência, os cursos de formação de professores terão de trabalhar com alunos desestimulados e pouco empenhados, o que se refletirá negativamente em seu desempenho (SAVIANI, 2011, p. 17).
}

E estes problemas são considerados nas famílias brasileiras quando se projeta uma formação superior para os jovens. Porque "as condições de trabalho docente têm um impacto decisivo na formação, uma vez que elas se ligam diretamente ao valor social da profissão" (SAVIANI, 2011, p. 17). 
Por consequência, a influência familiar referente à escolha do curso de graduação pelo discente, de acordo com os respondentes desta questão, observa-se uma dicotomia existente entre a visão de uma carreira docente que atrai pelas virtudes e importância social que detêm, e a consciência da precarização da profissão e desvalorização salarial no Brasil.

\section{A "percepção sobre a formação recebida"}

Sobre a formação recebida, 29 respondentes (74,3\%) consideraram-na como transformadora, uma proporção de satisfação maior do que na pergunta “ $O$ curso de graduação escolhido atendeu as suas expectativas de formação até agora?", com 22 respostas de 34 respondentes desta questão.

Isto evidencia que, para alguns, talvez, mesmo recebendo uma formação que não atenda às suas expectativas, ainda assim a experiência adquirida na passagem pela Universidade teve um significado importante. Em geral, pode-se inferir que a maioria dos respondentes está satisfeita com a formação recebida e a considera como transformadora na sua vida. Os motivos são variados, mas apontam algumas questões importantes que merecem destaque.

Dentre as falas dos 22 respondentes com expectativas de formação atendidas, os professores mereceram destaque, obtendo menção, principalmente, no tocante às suas qualificações, como pode ser visualizado nas respostas a seguir:

Sim. A maioria dos professores possuem alto nível de formação e os conteúdos foram muito relevantes (R9).

Sim. Devido aos ótimos professores e o conhecimento assimilado, além do desenvolvimento do senso crítico (R18).

Sim. Tive professores qualificados e com compromisso de desenvolvimento do aluno (R34).

Este destaque à qualificação docente foi confirmado na pergunta "qual papel tiveram os professores nesta transformação?", em que 17 dos 26 respondentes proclamaram os seus professores como "fundamentais" ao considerarem a sua formação transformadora. Como mostra os relatos dos respondentes a seguir:

Foram fundamentais (R7).

Os principais personagens do meu desenvolvimento até aqui (R26).

Total. Trouxeram novas formas de ver o mundo e novas possibilidades sobre o que eu já achava que sabia (R4).

Tiveram um papel imensurável e ímpar para a minha formação (R12).

O Projeto Político Pedagógico do Instituto Multidisciplinar (IM) exigia a qualificação de mestres e doutores aos primeiros 70 docentes contratados mediante concurso público. A Revista Interinstitucional Artes de Educar. Rio de Janeiro, V. 4, N.1- pág. 186 - 203 - (jan. - abr. de 2018): "Questões contemporâneas sobre a Educação Especial na Perspectiva da Educação Inclusiva" 
qualificação docente pôde proporcionar a elaboração dos projetos de pesquisa e pós-graduação, conquistas de financiamentos em editais públicos, e trazer para a formação dos licenciandos do IM ferramentas que possibilitaram estar em dia com as últimas descobertas, uma das características do século XXI.

Zainko (2010) destaca a necessidade de levar para os processos de formação dados da realidade e instrumentos eficazes de gerenciamento do conhecimento. Pois a gestão do conhecimento na formação dos professores é um processo sistemático, articulado e intencional, de disseminação e apropriação de conhecimento e tem o propósito de atingir a excelência da formação e por consequência a qualidade da educação.

Porém, mesmo diante da excelência acadêmica dos docentes destes cursos de licenciatura, alguns aspectos negativos merecem destaque nesta análise. Pois, ressalta-se que 10 respondentes afirmaram não terem suas expectativas atingidas na graduação, apontando problemas como infraestrutura deficiente, por exemplo, conforme destaca o respondente 5: "Não. Apesar dos ótimos professores, a estrutura sucateada da Universidade influenciou na oferta de disciplinas".

Dentre os problemas citados, aponta-se como o de maior referência a falta da prática docente dentro do processo formativo, mencionado por 6 respondentes:

\footnotetext{
Não. Tratando-se de licenciatura gostaria de um curso com mais foco no ensino (R1).

Não. Senti falta de mais prática docente para minha formação e para realidade e necessidade do mercado de trabalho (R3).

Não. As noções para licenciatura foram poucas. $\mathrm{O}$ curso parece ser mais voltado para o bacharelado (R7).

Não. O campo educacional é muito restrito e fechado. Além das divergências e burocracias encontradas que tornam a prática muito mais difícil do que a teoria aprendida na Universidade (R12).

Não tive formação adequada nem para pesquisa, nem para licenciatura, com falhas principalmente na oferta de disciplina pra um pré-projeto de pesquisa e nas disciplinas de estágio (R25).

Não. Porque o curso está voltado mais para a pesquisa (bacharelado) do que para a formação de professores (licenciatura). (R29).
}

Nóvoa (2009) considera positiva a qualificação acadêmica dos formadores de professores, sobretudo no que diz respeito à proximidade com a investigação e ao rigor científico, mas a acentuada valorização do papel dos "cientistas da educação" e do seu conhecimento teórico ou metodológico na formação docente não pode ocorrer em detrimento dos professores e do seu conhecimento prático.

A formação docente, considerando os saberes dos professores e seus trabalhos cotidianos, 
é a ideia de base das reformas que vêm sendo realizadas na formação dos professores em muitos países nos últimos dez anos. Ela expressa a vontade de encontrar, nos cursos de formação de professores, uma nova articulação e um novo equilíbrio entre os conhecimentos produzidos pelas universidades a respeito do ensino e dos saberes desenvolvidos pelos professores em suas práticas cotidianas (ZAINKO, 2010, p. 124).

O Projeto Político Pedagógico do Instituto Multidisciplinar previu na matriz curricular inicial dos seus cursos uma identidade multi e interdisciplinar pautada numa base teórico-prática. Pois para todos os cursos previa atividades acadêmicas obrigatórias, a saber: as atividades acadêmico-científico-culturais (mínimo de 200 horas), o Estágio Curricular Supervisionado (mínimo de 400 horas) e um trabalho de conclusão de curso (mínimo de 100 horas).

As matrizes curriculares dos cursos de licenciatura do IM foram reformuladas em 2008 pelo Programa Institucional de Formação de Professores para a Educação Básica da UFRRJ ${ }^{2}$, que reorganizou as composições curriculares dos cursos de licenciatura desta Universidade, se adequando as Diretrizes Curriculares Nacionais para a Formação de Professores da Educação Básica ${ }^{3}$.

É importante destacar que as Diretrizes Curriculares Nacionais para a Formação de Professores da Educação Básica, segundo Freitas (2007), provocaram movimentos diferenciados no desenvolvimento e materialização da organização curricular em cada IES, rebaixando as exigências do campo da teoria pedagógica na organização curricular. A carga horária e o tempo de duração, o espaço destinado aos estudos do campo da educação, diluídos nas horas destinadas aos conteúdos científicos culturais e a concepção de práticas e estágios supervisionados, que descaracteriza o ensino como atividade essencial, vão se revelando como um rebaixamento na qualidade da formação teórica, no campo das Ciências da Educação, mas também no campo das áreas específicas.

Desta forma, ainda segundo esta autora, a redução do espaço dos fundamentos epistemológicos e científicos da educação nos processos formativos, e a prevalência de uma concepção conteudista e pragmática de formação de professores, ancoradas na epistemologia da prática e na lógica das competências, vem produzindo novas proposições para as licenciaturas, em continuidade às políticas neoliberais do governo do presidente Fernando Henrique Cardoso.

Diante desta discussão, a valorização da prática educativa se torna importante desde que possibilite um momento de retomada e de reflexão de experiências e questionamento de rotinas. Como destacado a seguir:

\footnotetext{
${ }^{2}$ UFRRJ/Deliberação CEPE n ${ }^{\circ} 138$, de 11 de dezembro de 2008.

${ }^{3}$ Resoluções CNE/CP n ${ }^{\circ}$ 1, de 18 de fevereiro de 2002, e CNE/CP n ${ }^{\circ}$ 2, de 19 de fevereiro de 2002.
} 
Até agora a formação para o magistério esteve dominada, sobretudo, pelos conhecimentos disciplinares, conhecimentos esses geralmente produzidos em uma redoma de vidro, sem nem uma conexão com a ação profissional, devendo, em seguida, serem aplicados na prática por meio de estágios ou de outras atividades de gênero. Atualmente essa visão disciplinar e aplicacionista da formação profissional não tem mais sentido, não somente no campo do ensino, mas também nos outros setores profissionais (ZAINKO, 2010, p. 124).

Neste caso, o professor consciente do seu papel também de investigador, vai se apropriando como sujeito dos conhecimentos que ele mesmo gerou e pode rever sua prática, ampliando a compreensão das mudanças que o atingem. Pois a sociedade atual exige no ambiente de formação um conhecimento teórico-prático de uma sala de aula que se projeta para o mundo, por exemplo, através da internet.

Ao analisar as respostas sobre a formação recebida como transformadora, além da ascensão social e emprego, existem valores que compõem o processo formativo que se constituem como um fator importante para o desenvolvimento humano. Este fato fica evidente na maior parte dos relatos, como, por exemplo, do respondente 8: "Sim. Os ensinamentos transmitidos mudaram muito minha forma de ver o mundo".

De acordo com Gramsci (1982), o papel do ensino na sociedade (escola unitária) permitiria às classes desfavorecidas o acesso aos códigos dominantes que faria com que o jovem aprenda a pensar concretamente, transformar, homogeneizar de acordo com um processo de desenvolvimento orgânico que eleve do simples senso comum ao pensamento coerente e sistemático.

Desta forma, ainda segundo este autor, a passagem pelo ensino superior é vista como um processo de construção de uma concepção de mundo, em suas dimensões política, econômica e social, na condição de sujeitos livres que, pela sua ação consciente e coletiva, constroem, não só o mundo em que vivem, como a si mesmos.

Os relatos abaixo demonstram, segundo suas palavras, o significado para suas vidas da formação recebida:

Houve mudança em minha forma de pensar e em meu senso crítico em diversas situações. (R25).

Como instrumento de estimular um pensamento crítico sobre questões sociais e culturais, a formação recebida no meu curso foi de suma importância. (R19).

Aprendi muito, mudei minha forma de pensar e me tornei mais crítica. (R13).

Lógico! Estar numa Universidade faz você criar conhecimento para além da sala de aula! Conhecer novas pessoas, novas situações... Tudo é aprendizado. (R10).

A "Comisión Económica para América Latina y el Caribe" CEPAL (2007) também destaca a educação como elemento fundamental para o desenvolvimento humano, pois grande 
parte do conhecimento adquirido através processos de formação são de caráter adaptativo, que facilita o acesso a novos conhecimentos e avanços sobre a realidade e sua transformação.

Os relatos a seguir são exemplos dos significados que a formação em nível superior pode representar para um estudante:

Me transformei num melhor cidadão (R1).

Ter uma graduação me possibilita abrir novas portas não só na vida financeira, como acadêmica (R7).

Era um sonho meu cursar o $3^{\circ}$ grau, e Pedagogia melhorou a minha condição no meu trabalho como agente de educação infantil (R15).

Me deu emprego (diretamente) e pude casar (indiretamente).(R12).

Desta forma, as menções dos respondentes à "qualificação técnica", "oportunidades (emprego/estudo)" e "crescimento pessoal/conhecimento" indica que a passagem pelo ensino superior pode capacitar as pessoas para os seus diversos projetos, pois de acordo com o relatório da Cepal (2007), os conhecimentos acerca do mundo, assim como as experiências adquiridas, permitem as pessoas interagir, integrar e assumir diferentes papéis na vida social.

Portanto, observa-se através das questões que envolvem a segunda categoria de análise, que, de forma geral, os discentes respondentes estão satisfeitos com a formação recebida e a consideram transformadora na sua vida, com destaque para a elevada qualificação do corpo docente. Como destaque negativo, de forma geral, observam-se algumas deficiências em relação à infraestrutura e a falta de prática docente dentro do processo formativo.

\section{Considerações Finais}

A criação de um campus universitário observado sob o aspecto de uma política pública de expansão do ensino superior retrata um grande desafio, que consiste em entender a aplicabilidade do resultado de uma política educacional macro, no nível local; neste caso em específico, na UFRRJ - Campus Nova Iguaçu. Os relatórios de políticas públicas como esta, geralmente contém números e estatísticas, mas deixam a desejar no aprofundamento qualitativo, principalmente não ouvindo o público alvo que vivenciou a referida política.

Um estudo como este, característico de uma pesquisa exploratória, permitiu obter respostas sobre o impacto do processo de formação de professores, pela inserção de jovens alijados de oportunidades, pelos quais a política pública de expansão e interiorização do ensino superior no governo do presidente Luis Inácio Lula da Silva foi idealizada e promovida.

Esta constatação pode avaliar com sucesso parte dos objetivos desta política educacional, como também enriquecer a análise dos aspectos proeminentes do levantamento de campo. Como 
reforça Hofling (2001), a explicação quanto ao sucesso ou fracasso de uma política ou programas elaborados depende dos fatores culturais, àqueles que historicamente vão construindo processos diferenciados de representações, de aceitação, de rejeição, de incorporação das conquistas sociais por parte de determinada sociedade.

Dentre os principais aspectos apontados no levantamento de campo, além da proximidade e qualidade do campus universitário criado, outros fatores também influenciaram a escolha do curso de graduação, como: a identificação com a docência ou a disciplina à qual lecionará como professor(a) e a garantia de um emprego.

Outro aspecto que pode interferir na escolha de um curso de licenciatura foi a dicotomia existente entre a visão de uma carreira docente que atrai pelas virtudes e importância social que detêm, e a consciência da precarização da profissão e desvalorização salarial no Brasil.

A percepção dos discentes participantes do levantamento de campo sobre a formação recebida na UFRRJ foi ao encontro das outras questões abordadas nas categorias de análise, pois destacou que a experiência adquirida na passagem pela Universidade foi considerada importante, apesar das dificuldades apontadas.

Dentre os aspectos apontados como fundamentais para compor positivamente suas expectativas de formação, foi citada a qualificação dos professores. O currículo dos docentes do Campus Nova Iguaçu da UFRRJ desde sua criação tem pontuação alta nas avaliações de curso realizadas pelo MEC, confirmando esta percepção discente.

Porém, mesmo diante da excelência acadêmica dos docentes destes cursos de licenciatura, alguns aspectos negativos foram apontados pelos estudantes, tais como: infraestrutura deficiente e, principalmente, a falta da prática docente dentro do processo formativo.

Os desafios atuais exigem no ambiente de formação um conhecimento teórico-prático que se contraponha a visão exclusivamente disciplinar da formação. Os estágios curriculares, por exemplo, poderiam ser mais utilizados como um instrumento de valorização da prática educativa, possibilitando um momento de retomada e de reflexão de experiências e questionamento de rotinas. Pois o papel do estágio reforça a práxis no processo formativo e a inserção do discente nos setores da economia, promovendo a integração universidade/sociedade.

Como ressalva, é importante destacar que a prática, quando aplicada dentro da lógica das competências, pode descaracterizar o ensino como atividade essencial e rebaixar a qualidade da formação teórica. Neste caso, na concepção teórico-prática, cabe ao professor rever constantemente sua prática docente, atribuindo-lhe novos significados através da apropriação como sujeito dos conhecimentos que ele mesmo gerou e, assim, obter maior espaço para a Revista Interinstitucional Artes de Educar. Rio de Janeiro, V. 4, N.1- pág. 186 - 203 - (jan. - abr. de 2018): "Questões contemporâneas sobre a Educação Especial na Perspectiva da Educação Inclusiva" 
compreensão das mudanças que o atingem. Por isso, a qualidade social vislumbrada para as IES deve garantir características inovadoras e ousadas aos processos de formação.

Outros componentes importantes na caracterização da sua formação como transformadora na sua vida surgiram da percepção dos discentes desta pesquisa, como: "qualificação técnica", "oportunidades (emprego/estudo)" e "crescimento pessoal/conhecimento".

De acordo com estes aspectos, segundo a própria percepção destes discentes, a passagem pelo ensino superior parece tê-los capacitados para os seus diversos projetos, vista como um processo de construção de uma concepção de mundo, em suas dimensões política, econômica e social, que resulta em cidadãos conscientes do seu papel social e da sua importância para o desenvolvimento da região onde estão inseridos.

\section{Referências}

BARDIN, Laurence. Análise de Conteúdo. Lisboa. Ed. 70. 1979.

BRASIL. Lei $n^{\circ}$ 10.861, de 14 de abril de 2004. Institui o Sistema Nacional de Avaliação da Educação Superior - SINAES e dá outras providências. Diário Oficial da União, Brasília, DF, 15 abr. 2004. Seção 1, p. 3-4.

. Ministério da Educação. Conselho Nacional de Educação (CNE). Resolução $\overline{C N E / C P n^{\circ}}$ 1/2002. Institui Diretrizes Curriculares Nacionais para a Formação de Professores da Educação Básica, em nível superior, curso de licenciatura, de graduação plena. Diário Oficial [da] República Federativa do Brasil, Poder Executivo, Brasília, DF, 04 mar. 2002. Seção 1, p. 8.

. Ministério da Educação. Conselho Nacional de Educação (CNE). Resolução $\overline{C N E / C P n^{o}}$ 2/2002. Institui a duração e a carga horária dos cursos de licenciatura, de graduação plena, de formação de professores da Educação Básica em nível superior. Diário Oficial [da] República Federativa do Brasil, Poder Executivo, Brasília, DF, 04 mar. 2002. Seção 1, p. 9.

. Ministério da Educação. Instituto Nacional de Estudos e Pesquisas Educacionais (INEP). Censo da Educação Superior. Disponível em: <http://portal.inep.gov.br/web/censo-daeducacao-superior>. Acesso em: 20 mai. 2015.

CASTLES, Stephen. Estudar as transformações sociais. Sociologia, Problemas e Práticas. Oeiras, n. 40, p. 123-148, set. 2002. Disponível em <http://www.scielo.mec.pt/scielo.php?script=sci_arttext\&pid=S087365292002000300008\&lng= pt\&nrm=iso>. Acesso em 19 jul. 2016.

CEPAL-COMISSÃO ECONÔMICA PARA A. LATINA E O CARIBE. La pobreza a fines de los años noventa, 2007.

FREITAS, Helena Costa Lopes de. A (nova) política de formação de professores: a prioridade postergada. Educação \& Sociedade, v. 28, n. 100, p. 1203-1230, 2007. 
GATTI, Bernadete Angelina; BARRETO, Elba Siqueira de Sá. Professores do Brasil: impasses e desafios. Brasília: UNESCO, 2009.

GOMES, Romeu. Análise e interpretação de dados de pesquisa qualitativa. In MINAYO, M. C. de S. (org.); DESLANDES, S. F.; GOMES, R. Pesquisa Social: teoria, método e criatividade. 28. ed. Petrópolis, RJ: Vozes, 2009.

GRAMSCI, Antonio. Os intelectuais e a organização da cultura. Trad. Carlos Nelson Coutinho. Rio de Janeiro: Civilização Brasileira, 1982.

HÖFLING, Eloisa de Mattos. Estado e políticas (públicas) sociais. Cadernos Cedes, v. 21, n. 55, p. 30-41, 2001.

INSTITUTO BRASILEIRO DE GEOGRAFIA E ESTATÍSTICA. Censo 2010, Cidades @. Rio de Janeiro. Disponível em: <http://www.cidades.ibge.gov.br> Acesso em: 29 jun. 2014.

MATTAR, Fauze Najib. Pesquisa de Marketing: metodologia, planejamento. São Paulo: Atlas. 1996.

MINAYO, Maria Cecília de Souza. (org.); DESLANDES, Suely Ferreira; GOMES, Romeu. Pesquisa Social. Teoria, método e criatividade. 28. ed. Petrópolis, RJ: Vozes, 2009.

NÓVOA, Antônio. Imagens do futuro presente. Lisboa, Portugal: EDUCA, 2009.

SAVIANI, Dermeval. Formação de professores no Brasil: dilemas e perspectivas. Poíesis Pedagógica, v. 9, n. 1, p. 07-19, 2011.

SGUISSARDI, Valdemar. Modelo de expansão da educação superior no Brasil: predomínio privado/mercantil e desafios para a regulação e a formação universitária. Educação \& Sociedade, v. 29, n. 105, p. 991-1022, 2008.

SOUZA, Renan Arjona de. O Significado Social da Política Pública de Expansão do Ensino Superior na Baixada Fluminense. 2016. 129p. Dissertação (Mestrado em Ciências) Universidade Federal Rural do Rio de Janeiro, 2016.

UFRRJ. Programa Institucional de Formação de Professores para a Educação Básica. Deliberação CEPE nº 138 de 11 de dezembro de 2008. Disponível em: <http://r1.ufrrj.br/graduacao/arquivos/docs_academico/delib_cepe_138_2008.pdf >. Acesso em: 20 mar. 2016.

- Projeto Político Pedagógico do Instituto Multidisciplinar da UFRRJ (PPP-IM). 2006. Deliberação CONSU n ${ }^{\circ} 04$ de 30 de março de 2006. Disponível em <http://institucional.ufrrj.br/soc/>. Acesso em: 15 abr. 2016.

ZAINKO, Maria Amélia Sabbag. Políticas de formação de professores na universidade pública: uma análise de necessidades, entre o local e o global. Educar em Revista, n. 37, 2010. 


\footnotetext{
${ }^{\mathrm{i}}$ Doutorando pelo Programa de Pós-graduação em Educação, Contxtos Contemporaneos e Demandas populares da Univerdade Federal Rural do Rio de Janiero (PPGEduc/UFRRJ). ii Doutora em Ciências Sociais em Desenvolvimento, Agricultura e Sociedade pela UFRRJ e Professora Associado da Universidade Federal Rural do Rio de Janeiro (UFRRJ).
} 